\title{
ANALYZING THE COMPUTER-AIDED MAINTENANCE DATA OF A COMMERCIAL BUILDING COMPLEX
}

\author{
Joseph H.K. Lai* and Francis W.H. Yik \\ Department of Building Services Engineering, Hong Kong Polytechnic University, Hong kong \\ *Corresponding author (bejlai@polyu.edu.hk)
}

\begin{abstract}
Commercial buildings in metropolises are increasing in number or in sophistication or both. The facilities therein, including building works and services installations, entail effective maintenance to ensure satisfactory performance. Owing to uncommon use of fully-automated maintenance systems and concerns with disclosure of maintenance data, there are so far very limited research studies on maintenance performance in such buildings to inform improvements. A landmark commercial building complex in Hong Kong, consisting of 60 storeys of office premises atop 15 storeys of shops, has been equipped with a computer-aided system (CAS) to record its maintenance data in a semi-automated manner. Reported in this paper is an exploratory study on the maintenance records retrieved from the CAS of that building for a period of 12 months. The study revealed that the amounts of maintenance work orders pertaining to the office and the shop areas were comparable but the downtimes of facilities in the office area were generally shorter. The technicians responded promptly to the majority of the works, including electrical, air-conditioning, builder's work, and plumbing and drainage, and a significant correlation between the downtimes and the volumes of work orders was observed. Further investigations are needed to obtain a more detailed picture of the demand, manpower utilization and performance of the maintenance works.
\end{abstract}

Keywords: Commercial building, Computer-aided Wystem, Facility Management, Maintenance, Performance Evaluation

\section{INTRODUCTION}

Commercial buildings in metropolises are equipped with a wide range of facilities, including building works (e.g. fabric and finishes) and building services installations (e.g. air-conditioning and electrical systems). Users' expectation, in respect of the reliability and operational performance of these facilities, is becoming increasingly demanding, which can only be met with effective maintenance works.

Since reliability of facilities is a critical concern in industrial sectors, such as manufacturing and aerospace, computerized maintenance management systems (CMMS) are extensively used to keep track of the operational status of and maintenance works for their facilities [1]. In contrast, building works and services installations in commercial buildings are less critical. For some essential facilities, e.g. transformers for electricity supply, the desired reliability level is typically attained by provision of standby equipment, e.g. a standby generator. Consequently, it becomes hard to justify the adoption of CMMS in commercial buildings solely on reliability grounds.
Nevertheless, as unveiled in an earlier study [2], the highly substantial manpower cost for maintaining commercial buildings necessitates proper monitoring and evaluation of the associated human resources. The absence of CMMS coupled with concerns of disclosing sensitive information about maintenance works of commercial buildings (e.g. rate of equipment failure and repair cost) [3] have seriously constrained research studies in this area while maintenance data continue to be underutilized [4] for informing improvements, both on performance of facilities and on their cost-effectiveness.

As an attempt to probe into the maintenance data of commercial facilities, a pilot empirical study had already been carried out based on the CMMS data of a hotel [5]. In order to investigate further into the maintenance data of other types of commercial buildings, an exploratory study was carried out on a building complex in Hong Kong, which comprises both office and retail premises. The maintenance data retrieved from the complex's computer- 
aided system (CAS) and the information collected from its maintenance staff were analyzed. In the following, the data collection process and the types of data collected are described, followed by a series of analyses of the findings, including the workload, outcome and labor resources of the maintenance works provided for the complex.

\section{DATA COLLECTION}

Located at the city centre, the building complex selected for this study consists of a 60 -storey $\left(71,535 \mathrm{~m}^{2}\right)$ office tower built over a 15 -storey $\left(55,742 \mathrm{~m}^{2}\right)$ shopping mall. Since its occupation four years ago, office premises in the complex have been fully occupied and its shopping mall is kept busy by tourists and local shoppers.

The maintenance team of the complex, having 24 technicians at maximum, looked after all the corrective and preventive maintenance works except that the statutory works (e.g. regular lift inspections) were outsourced from registered contractors [6]. A CAS, which involved the use of an electronic spreadsheet by an operator, was utilized to record the maintenance work orders in a semiautomated manner.

Supported by the Chief Technical Manager of the building complex, a meeting was held with his maintenance team, during which the study team explained the purpose and methodology of the study and the kinds of data needed. Meanwhile, the maintenance team informed about their operations, including how their maintenance works are organized, how the work orders are issued and executed, and how the status of the orders are reported and recorded in the CAS.

Subsequent to the meeting, the study team was guided by the maintenance team to walk through the main areas of the building to obtain an overview of its physical and operational characteristics. Then, a range of data records were collected through a series of post-meeting communications. They include: i) the electronic files recording the information of every work order over a period of 12 months; ii) the duty schedule of each maintenance worker; and iii) the factsheets showing the maintenance set-up and the operation periods and layouts of various areas of the building.
Before analyzing the data in full swing, their accuracy and reliability were checked. The queries so found, in general, were readily resolved upon seeking clarifications from the maintenance team. Inspecting across the work orders records, however, identified some cases which do not conform to the normal sequence of actions (see Fig. 1). Among the 17,364 orders issued, 388 were recorded without arrival time, leave time or complete time. Another group (632 orders) was recorded with a false time sequence, e.g. the issue time is after the arrival time, etc. With these defective data sets discarded, 16,344 orders were included in the following analysis.

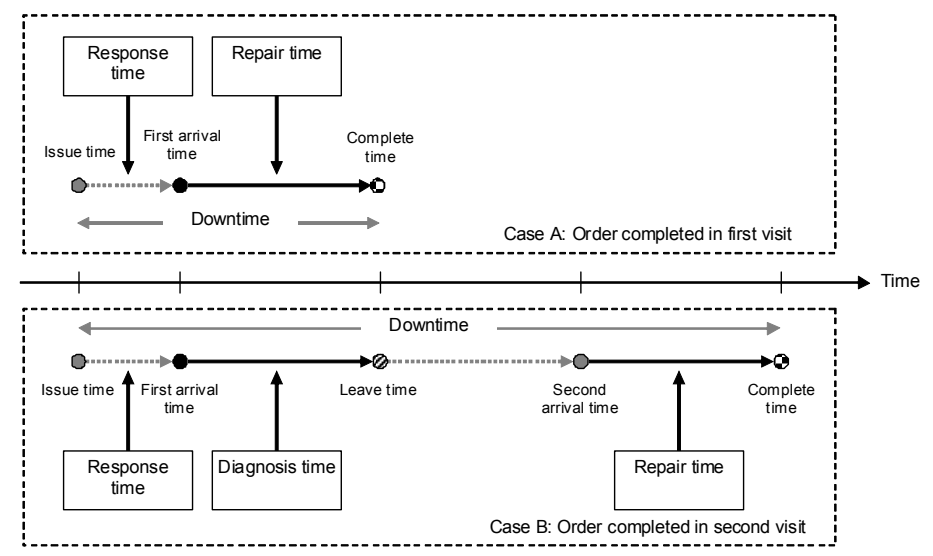

Fig. 1 Timeline of work orders

\section{ANALYSIS AND DISCUSSION}

\subsection{Volumes and types of work orders}

The analyzable orders were grouped according to where they were done and the trades and natures of the works involved. Table 1 shows the proportions of these groupings based on the number of work orders. With the majority being issued for the shop and office premises, a negligible amount of orders, classified as "Others", was issued for some ad-hoc works required by the adjacent hotel. Linked with the building complex via a footbridge, this hotel belonged to the same owner of the complex but its maintenance works were basically handled by a team independent from that covered in the present study.

Table 1 Proportions of different groups of work orders

\begin{tabular}{ll|ll|ll}
\hline Area & No. & Trade & No. & Nature & No. \\
\hline Shop & $58.0 \%$ & BW & $21.7 \%$ & General & $88.1 \%$ \\
Office & $41.7 \%$ & EE & $33.0 \%$ & Schedule & $9.6 \%$ \\
Others & $0.3 \%$ & BMS/ELV & $0.4 \%$ & Emergency & $1.8 \%$ \\
& & FS & $2.2 \%$ & Special & $0.5 \%$ \\
& & AC & $26.6 \%$ & & \\
& & PD & $16.1 \%$ & & \\
\hline
\end{tabular}


Grouping the orders by work trades found that the dominant trade was electrical (EE), followed by airconditioning (AC), builder's work (BW), and plumbing \& drainage (PD). There were a small number of fire services (FS) orders and those issued for the building management system (BMS) / extra low-voltage (ELV) works were even less. When grouped by work natures, the vast majority of the orders were for general corrective maintenance works. About one-tenth were preventive maintenance works performed on a scheduled basis. Very few were of an emergency or a special nature.

\subsection{Response time, repair time and downtime}

A summary of the means and standard deviations (S.D.) of the response time, repair time and downtime (in minutes) determined based on all the orders and those pertaining to the shop and office areas are shown in Table 2. The mean values of response time, between 3.4 hours and 4.0 hours, seem unreasonably long. The counterparts of repair time and downtime, which ranged between 26.2 hours and 74.2 hours, were even longer. This observation is due to the fact that for some orders, the technicians responded within the day on which the orders were issued but the needed repair work could not be finished in their first visit to the scene. The causes for this include: i) the materials or tools required for accomplishing the order were not readily available at the time of the first visit; ii) the technician found himself incapable of doing the repair work required; iii) the technician considered the requested work noncritical while he concurrently had another more critical problem to fix; iv) the requested work was beyond his scope of duties, e.g. a work that should be borne by the tenant instead of the landlord; and v) the time of the first visit was close to the end of the technician's duty period on the same day and so he could only finish part of the required work.

Table 2 Response time, repair time and downtime

\begin{tabular}{lllllll}
\hline & \multicolumn{2}{c}{ Response } & \multicolumn{2}{c}{ Repair } & \multicolumn{2}{c}{ Down } \\
& Mean & S.D. & Mean & S.D. & Mean & S.D. \\
\hline \multirow{2}{*}{ Shop } & 205.6 & 281.7 & 4246.0 & 14914.2 & 4451.6 & 14929.1 \\
Office & 241.4 & 2044.3 & 1573.7 & 9261.0 & 1815.1 & 9473.5 \\
All & 220.5 & 1337.6 & 3129.9 & 12920.5 & 3350.3 & 12992.7 \\
\hline
\end{tabular}

The majority (10,944 nos., $67.0 \%)$ of the work orders were completed in the first visit. Based on the downtimes (in minutes) of this group of orders, a summary of statistics was prepared (Table 3), showing the fractions and values of mean, S.D. and coefficient of variation $\left(\mathrm{C}_{\mathrm{v}}\right)$.

Table 3 Downtime of orders completed in the first visit

\begin{tabular}{lllll} 
Area & Fraction & Mean & S.D. & $\mathrm{C}_{\mathrm{v}}$ \\
\hline All & $100 \%$ & 312.5 & 1649.7 & 5.3 \\
Shop & $45.1 \%$ & 275.5 & 311.0 & 1.1 \\
Office & $54.7 \%$ & 351.8 & 2344.4 & 6.7 \\
\hline
\end{tabular}

Disregarding 23 orders $(0.2 \%)$ which were issued for the other areas, the numbers of orders for the shops $(5,603)$ and offices $(5,318)$ were comparable. The fraction of the aggregate downtime of the office area exceeded that of the shop area by $9.6 \%$. The large S.D. and $\mathrm{C}_{\mathrm{v}}$ values of the office area indicate that the downtimes of its work orders were widely spread and highly variable. Overall, the mean downtime associated with a work order was over 5 hours and that pertaining to the office area was even close to 6 hours. A detailed scrutiny on the natures of the work orders found that such long downtimes were due to the long periods spent on the preventive maintenance works, which accounted for $9.6 \%$ of the number of all orders (Table 1).

With the preventive work orders segregated, the corrective work orders were subdivided into two groups - office and shop. Shown in Fig. 2 are the distributions of the response time, repair time and downtime of the "office" orders, which were prepared by counting the number of orders in each 5-minute interval. Clearly, the largest group of orders was repaired in 30 to 35 minutes. The response time curve resembles a decay pattern, with 1,133 orders attended by the technicians within 5 minutes. In contrast, no distinct observations are noted from the downtimes except that the amounts of orders generally declined with time. 


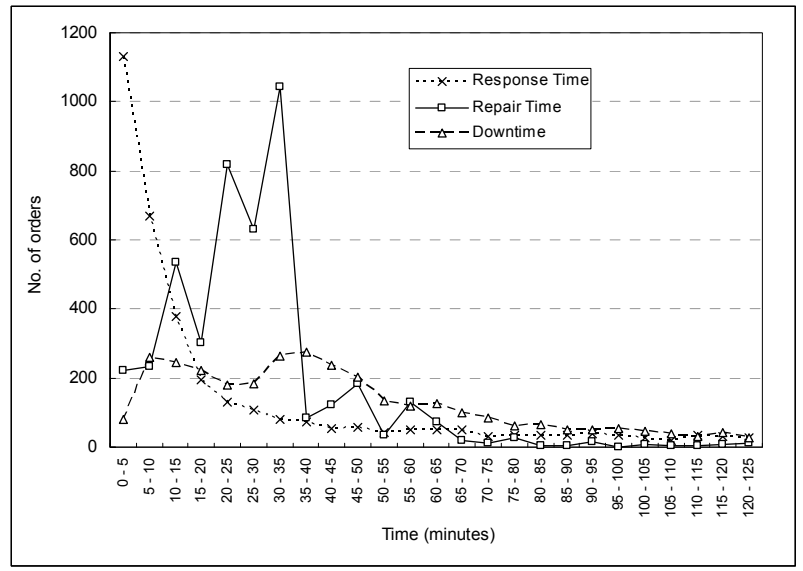

Fig. 2 Time distributions of orders for the office area

The time distribution patterns of the orders issued for the shop area, as graphed in Fig. 3, are similar to the counterparts of the office area. The major group of repair times was found between 30 and 35 minutes. The response time also shows a decay pattern, yet the number of orders of the largest group was only 784 . The downtime distribution peaked at 35-40 minutes, with 299 orders being in this group.

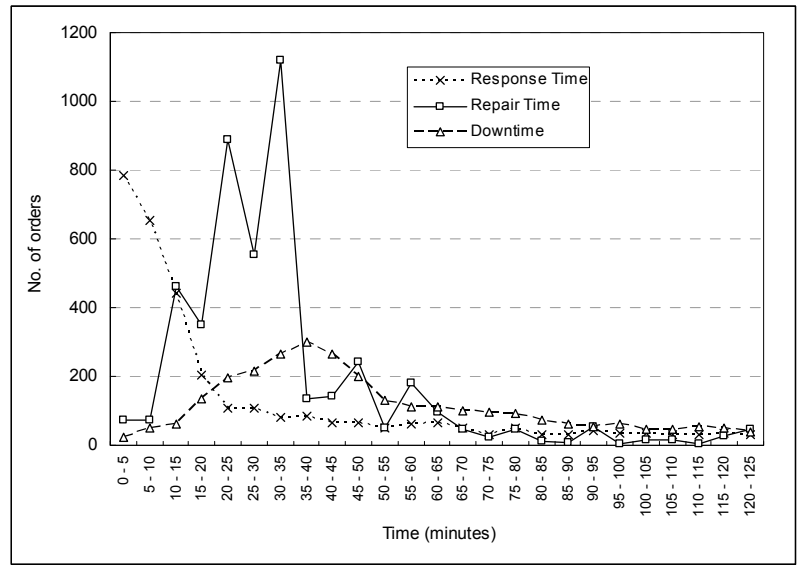

Fig. 3 Time distributions of orders for the shop area

Fig. 4 displays two cumulative downtime distribution curves, one for the orders issued for the office area and the other for the shop area. No crossovers are found between the curves. Based on a Pareto analysis, $80 \%$ of the "office" orders were completed in 220 minutes. But for the shop area, the same proportion of orders required 110 minutes more to complete. From this perspective, the maintenance works for the office area outperformed those for the shop area.

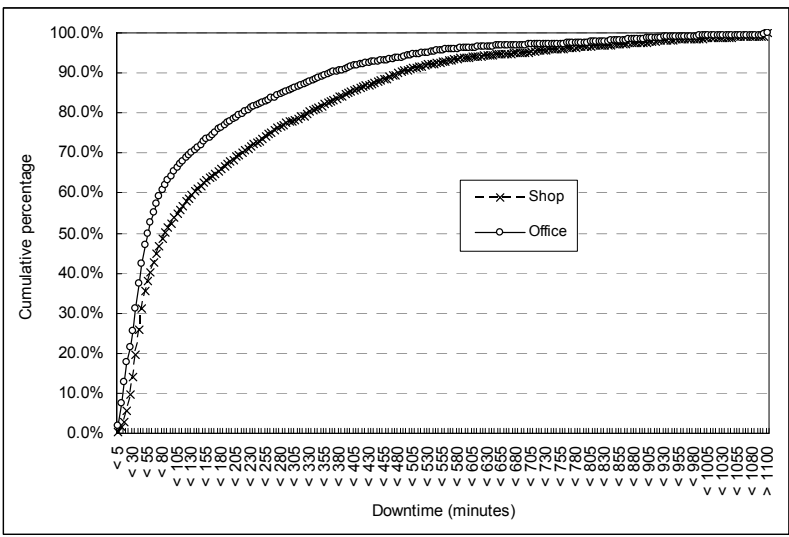

Fig. 4 Downtime distributions for office and shop areas

Because the downtime of an order comprises its response time and repair time, the cumulative proportion curves of these two components were prepared in order to identify their contributions to the difference in downtimes between the "office" and "shop" orders. As shown in Fig. 5, over half of the orders were responded promptly in less than 20 minutes. $80 \%$ of the repair works were completed within 35 minutes. Intriguingly, around $42 \%$ of the orders had a repair time shorter than their response time.

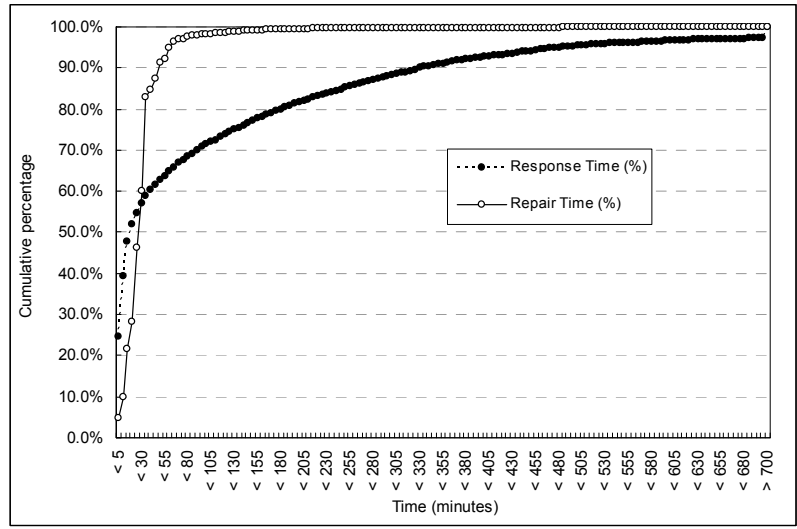

Fig. 5 Distribution of response and repair times (office) Likewise, the distributions of response time and repair time of the orders issued for the shops were analyzed by referring to Fig. 6. It shows that half of the orders were responded within 40 minutes, which doubled the counterpart of the office area. As compared to the finding of the office area, a longer period, i.e. 50 minutes, was needed for completing $80 \%$ of the repair works. A higher proportion (about 52\%) of the "shop" orders had a repair time shorter than their response time. 


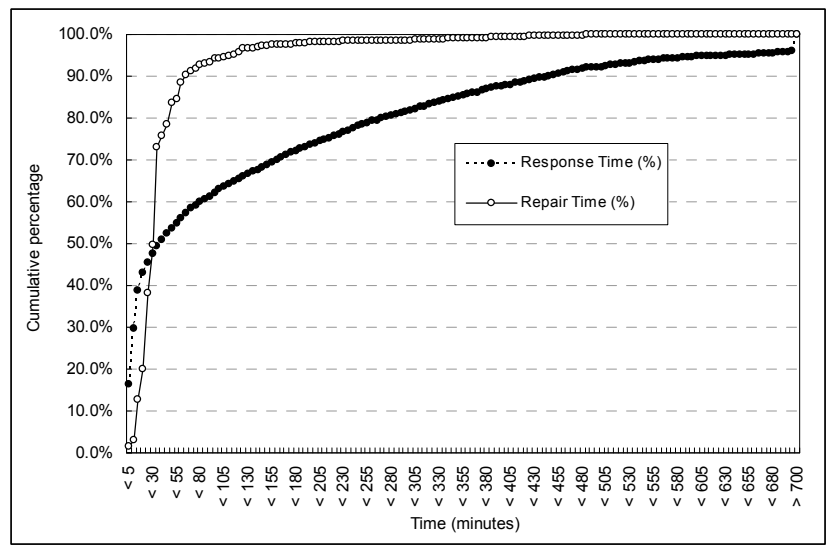

Fig. 6 Distribution of response and repair times (shop)

\subsection{Maintenance demand and manpower}

The outcome performance of the maintenance works, which can be reflected by the time distributions analyzed in the preceding section, may depend on a variety of factors, including the maintenance demand and the input resources for producing the works [5].

As Table 1 shows, over $97 \%$ of the maintenance demand belonged to four main trades of works (i.e. BW, EE, AC and PD). The downtimes associated with each of these trades of corrective work orders issued in each month were summed up, and the results are plotted in Fig. 7. Obviously, the AC downtimes were relatively steady. The downtimes of the other three trades, generally exhibiting an upward trend, fluctuated across the months and their peaks all occurred in December.

For identifying the level of input resources, the amount of man-hours of each trade of work was calculated for each month. This was done by counting the number of on-duty hours of every technician on each day as recorded in their monthly duty schedules. The results, as graphed in Fig. 8, show that the trade with the lowest yet the steadiest manpower level was PD. The manpower levels of EE and $\mathrm{AC}$ were highly variable, and the peak of the former was as high as 1,119.5 hours. A major reason for such variations, as revealed by an inspection on the duty schedules, is that the turnover rates of the $\mathrm{EE}$ and $\mathrm{AC}$ technicians were rather significant.

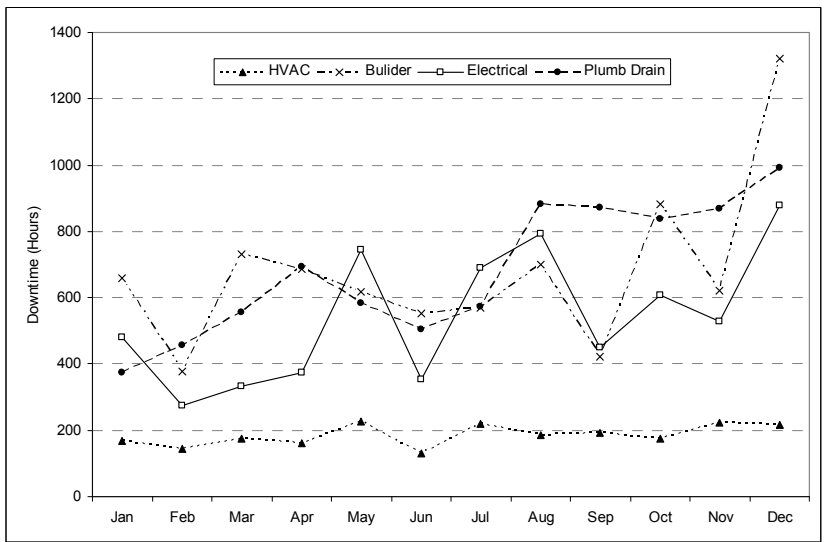

Fig. 7 Downtime variations of the four main trades

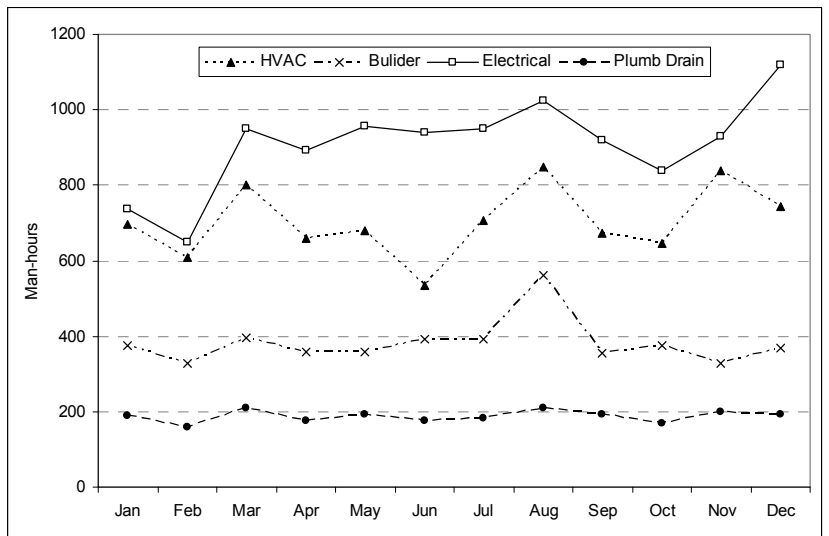

Fig. 8 Manpower variations of the four main trades

Furthermore, a cross-inspection between Fig. 7 and Fig. 8 noticed that the BW and PD downtimes were generally larger than their respective man-hours. The reasons for this include: i) sometimes the technicians had to handle multiple work orders; and ii) some multi-skilled technicians performed works both within and beyond their principal trades.

To test whether and to what extent the outcome performance of the maintenance works was correlated with the maintenance demand and input manpower, a series of correlation analyses was carried out. The Pearson product moment correlation coefficients, calculated based on the monthly amounts of work orders, man-hours and downtimes of each main trade, are summarized in Table 4. 
Table 4 Pearson product moment correlation coefficients

\begin{tabular}{lllll}
\hline Trade & & Man-hour & Order no. & Downtime \\
\hline AC & Man-hour & 1.000 & - & - \\
& Order no. & 0.300 & 1.000 & - \\
& Downtime & 0.591 & 0.705 & 1.000 \\
\hline BW & Man-hour & 1.000 & - & - \\
& Order no. & 0.250 & 1.000 & - \\
& Downtime & 0.121 & 0.585 & 1.000 \\
\hline EE & Man-hour & 1.000 & - & - \\
& Order no. & 0.522 & 1.000 & - \\
& Downtime & 0.660 & 0.765 & 1.000 \\
\hline PD & Man-hour & 1.000 & - & - \\
& Order no. & 0.477 & 1.000 & - \\
& Downtime & 0.331 & 0.850 & 1.000 \\
\hline
\end{tabular}

Across the trades, the largest coefficients (ranging from 0.585 to 0.850 ) were found with the correlation between the amount of order and downtime, indicating that there existed moderately to strongly positive correlations between them. In view of this finding, the linear regression line for each of the four trades was constructed, as shown in Fig. 9. As indicated by the values of the coefficients of determination $\left(\mathrm{R}^{2}\right)$, the goodness of fit of the regression line for the PD trade was the highest while that for the BW trade was the lowest.

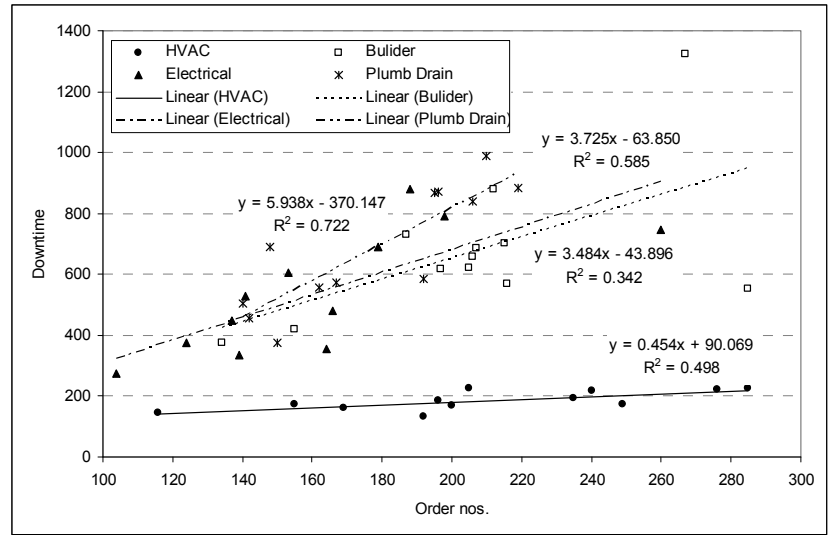

Fig. 9 Linear regression lines of the four main trades

\section{CONCLUSIONS}

This exploratory study has unveiled the comparable proportions between the maintenance work orders of the office and shop areas, with the downtimes of the former area being generally shorter. The majority of the four most demanding trades of works, namely electrical, airconditioning, builder's work, and plumbing and drainage, were promptly attended. The downtimes of these works were significantly correlated with their volumes of work orders rather than their manpower levels.

Further investigations are needed in order to obtain a more detailed picture of the maintenance works. Adopting a similar approach of this study, more studies on the maintenance works of other buildings can be carried out to provide more findings of this kind for benchmarking purposes.

\section{REFERENCES}

[1] Levitt, J., "CMMS - 9 plus 50 questions", Asset Management \& Maintenance Journal, Vol. 20(2), pp. 8-13. 2007.

[2] Lai, J.H.K., "Operation and maintenance budgeting for commercial buildings in Hong Kong", Construction Management and Economics, Vol. 28 (April), pp. 415-427, 2010

[3] Lai, J.H.K., Yik, F.W.H. and Jones, P., Expenditure on Operation and Maintenance Service and Rental Income of Commercial Buildings, Facilities, Vol. 26, No. 5/6, pp. 242-265, 2008.

[4] Lee, S. and Akin Ö., Shadowing tradespeople: Inefficiency in maintenance fieldwork, Automation in Construction, Vol. 18, pp. 536-546, 2009.

[5] Lai, J.H.K. and Yik, F.W.H., A Probe into the Facilities Maintenance Data of a Hotel, Building Services Engineering Research and Technology, 2011 (in press).

[6] Lai, J.H.K. and Yik, F.W.H., Law and building services maintenance in Hong Kong, Transactions, The Hong Kong Institution of Engineers, Vol. 11, No. 1, pp. 7-14, 2004. 